\title{
Impacts of crop raiding by wildlife on communities in buffer zone of Sakteng Wildlife Sanctuary, Bhutan
}

\author{
Sonam Tobgay ${ }^{1}$, Sonam Wangyel ${ }^{2}$, Kumbu Dorji ${ }^{3}$, Thinley Wangdi ${ }^{4}$ \\ 1,2,3,Sakteng Wildlife Sanctuary, Trashigang \\ Department of Forest and Park Services, Bhutan \\ ${ }^{4}$ Samtse Territorial Forest Division, Samtse \\ Department of Forest and Park Services, Bhutan
}

\begin{abstract}
:
This study was carried out in Sakteng Wildlife Sanctuary, Bhutan to assess the consequence of crop raided by conflict species in four villages located in the buffer zone. Data were collected through semi-structured household interviews, direct observation, and key informant interviews. The majority of households interviewed $(95.5 \%)$ reported the prevalence of crop depredation by wild animals. The results also indicated that crop loss was significant and more frequent near the forest edge compared to crops located distant from the forest. Porcupine was reported to be the most destructive wild animal followed by the monkey and wild pig. Wild animals caused considerable economic loss to households by raiding their crops. We propose collaboration between wildlife managers, researchers, and affected communities to come up with a sound management intervention strategy to lessen the crop raiding. For immediate and effective protection of the crops, we recommend the installation of solar and electric fencing to reduce the severity of crop raiding.
\end{abstract}

Keywords: Crop raiding, Human-wildlife conflict, wild animals, Bhutan, Sakteng Wildlife Sanctuary.

\section{Introduction}

Human Wildlife Conflict (HWC) arises when the needs of human and wildlife impact on each other [1]. HWC in the form of livestock and crop depredation, and damage to property has existed since the coexistence of human and wildlife in the same landscape sharing the resources [2]. Transformation of land use, encroachment, fragmentation, loss of habitat to suffice the need of growing human population and restoration of wildlife population through conservation initiatives has resulted in increased incidences of HWC [3], [4], [5], [6]. The propensity of HWC increases with proximity to settlements near protected areas where wildlife population density is higher [4], [5], [7], [8].

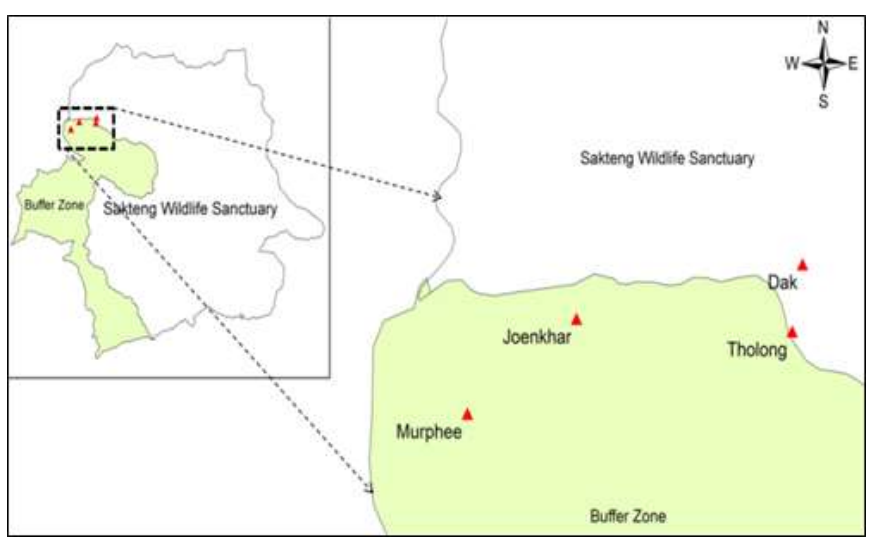

Figure 1: Map showing the location of the study site in context to Sakteng Wildlife Sanctuary

The loss of crops, livestock and human lives to wildlife represents the social and economic cost that affects the livelihoods, promotes poverty which may eventually lead to retaliation against conservation programs by the people. If the conservation programs are to succeed, then HWC needs to be 
reduced. Hence there is an urgent need to address the concerns of Bhutanese farmers by designing and implementing various plans aimed at managing the conflicts. HWC is also known to aggravate household psychological wellbeing, health, livelihoods, and food insecurity, which can be categorized as hidden social costs, indirect/opportunity costs and direct costs [9], [10], [11]. It is more intense where livestock holdings and agriculture are an important part of livelihoods [4]. However, relative damage greatly varies according to the quantity of land and livestock owned and people's economic dependence on these resources [7]

In Bhutan, the agriculture sector is one of the main economies with close to $50 \%$ of the rural population practicing subsistence farming [12]. Dominated by mountainous topography, only $2.93 \%$ of the land is used for agriculture production [13]. Management of protected areas in Bhutan allows human settlement and livestock grazing. People are considered an integral part of the successful management of protected areas. A major issue faced by agrarian societies nearby and within forested and protected areas is HWC [14]. Currently, with $51.4 \%$ of the land under the network of protected areas [15] and $71 \%$ national forest cover [16] in Bhutan HWC in the form of livestock depredation and crop damage is frequent.

HWC in Bhutan are skewed towards livestock depredation with very sparse empirical information involving crop damage in rural communities where small-scale agriculture plays a significant economic role. Therefore, the present study aims to determine the impact of crop damage by wildlife on the livelihoods of the small communities residing in the buffer zone of Sakeng Wildlife Sanctuary.

\section{Methodology}

\subsection{Study area}

Sakteng Wildlife Sanctuary (SWS) located in Trashigang district bordering with Indian state of Arunachal Pradesh is one of the ten protected areas in Bhutan. It has a responsibility of managing wild habitat and natural resource within the jurisdiction of Merak and Sakteng under Trashigang and a small portion of Lauri sub-district under Samdrupjonkhgar. Villages comprising of Joenkhar, Tholong, Muphee, and Dak falls within the periphery and buffer zone of the Sanctuary (Figure 1). These settlements are located at the lower elevations of approximately $1500 \mathrm{~m}$ dominated by mixed conifer species and practice subsistence agriculture. Subsistence agriculture is the mainstream occupation with carpentry, weaving, and painting as an additional source of income for the people. Approximately 80 households reside in these four villages which are now connected with farm roads. However, during the monsoon season accessibility of these villagers are at risk because of fragile geology which makes the road unstable. Maize is the main cereal crop cultivated for selfconsumption followed by dryland paddy and buckwheat.

\subsection{Data collection and analysis}

Settlement maps were overlaid on the zonation map to determine their location with context to the buffer zone of SWS. Four settlements were selected based on their location within and proximity to the buffer zone of the Sanctuary for the study. Adopting the random sampling technique with 10 percent confidence interval at 95 percent confidence level, crop raiding information from 44 out of approximately 80 households were collected using semi-structured questionnaires. For each household, we interviewed a person who has been in the village for more than a year and practices agriculture. The questionnaires were focused on types of crops cultivated, the pattern of crop raiding incidences, types of crops damaged, type of wild animal responsible for the crop damage, estimates of crop loss and coping strategies against crop raiding.

Data analysis was conducted using the statistical package for social science (SPSS 16.0). Descriptive statistics were used to interpret the data. The destructiveness of the individual animal to the crop were determined by assigning the different values; $5>3$ for highly destructive, $3>1$ for moderate and 1 for less destructive based on quantity and nature of damage experienced by the farmers. The opportunity cost was calculated based on the current minimum 
daily national wage rate of the country (i.e. 3.6 US\$ per day).

\section{Result and Discussion}

\subsection{Socio economic and cropping characteristics}

Respondents age gradation was within the range of 19 to 68 years (mean $=39.79 \& \mathrm{SD} \pm 13.63$ ). The majority of the women respondents were in the age category of $25-40(n=13)$ while the maximum of the male was within the category of $35-50(n=13)$. The size of the landholdings owned by the sampled households ranged from 0.15 to 7.06 acres with an overall mean of 1.34 acres (Table 1).

The main economic activity of the sampled households was subsistence agriculture dominated by dry land cultivation. Crops cultivated consisted of maize $(100 \%)$, dry land paddy $(27.3 \%)$, millet $(22.7 \%)$, wheat $(13.6 \%)$ and buckwheat $(9.1 \%)$. Maize is the main cereal crop in the study area. Annual mean per capita yield of crops by household is shown below (Table 2). Although crops are cultivated for domestic use, in case of surplus production, households sell and barter the produce to the people of Sakteng village (high altitude herder community). Amongst the crops grown in the study

area, maize is the only crop that is in surplus

$$
\text { production }(n=22) \text {. }
$$

Table 1: Landholding by a household in respective villages in the study area. Size of land owned by a household in the study area ranges from 0.15 to 7.06 acres with and overall mean of

\begin{tabular}{llcc}
\hline $\begin{array}{l}\text { S1. } \\
\text { no }\end{array}$ & $\begin{array}{l}\text { Types of crop } \\
\text { cultivated }\end{array}$ & $\begin{array}{c}\text { Mean } \\
\text { annual } \\
\text { yield (kg) }\end{array}$ & $\begin{array}{c}\text { No. of } \\
\text { cultivator } \\
(\mathrm{HH})\end{array}$ \\
\hline 1 & Maize & 1215.00 & 44 \\
2 & Wheat & 91.66 & 6 \\
3 & Millet & 40.00 & 10 \\
4 & Buckwheat & 21.50 & 4 \\
5 & Dryland paddy & 20.50 & 12 \\
\hline
\end{tabular}

\begin{tabular}{|c|c|c|c|c|}
\hline Sl.no & Village & $\begin{array}{c}\text { Avg. } \\
\text { acre/H } \\
H\end{array}$ & $\begin{array}{c}\text { Max. } \\
\text { acre/H } \\
\text { H }\end{array}$ & Min. acre/HH \\
\hline 1 & Dak & 0.79 & 2 & 0.15 \\
\hline 2 & $\begin{array}{l}\text { Joenkh } \\
\text { ar }\end{array}$ & 0.86 & 3 & 0.4 \\
\hline 3 & $\begin{array}{l}\text { Murph } \\
\text { ee }\end{array}$ & 0.9 & 2 & 0.78 \\
\hline 4 & $\begin{array}{l}\text { Tholon } \\
\mathrm{g}\end{array}$ & 2.46 & 7.06 & 0.26 \\
\hline
\end{tabular}

People also cultivate vegetables like potato, cabbage, cauliflower, chili, radish, pumpkin, garlic, beans and spinach both for domestic use and sale $(n=10)$ to supplement their crop income. Annual income from the sales of surplus crops by 22 households ranged from 50 US\$ to 208.3 US\$ with an overall mean income of 87.3 US\$. The other 22 households reported cultivating crops only for selfconsumption. Ten sampled households generated a mean annual income of 97.5 US\$ from the sales of vegetable (range8.3US\$ to 333.3US\$).

\subsection{Factors affecting crop yields}

Of the total sampled households, $95.5 \%$ reported crop damage by wildlife and consider it as the major problem followed by disease outbreak, natural calamities (failure of rain and damage by wind), damage by domestic animals and a shortage of draught power and labor as limiting factors that affect their production (Figure 2). Only $4.5 \%$ of interviewees reported no incidence of crop loss to wildlife since their land was located in the center of the settlement.

\subsection{Crop damage and economic loss}

Mean annual crop loss to wild animals in the study area was found to be $410 \mathrm{~kg} /$ household equivalent to 170.8 US\$ per household consisting mostly of maize ( $0.42 \mathrm{US} \$ / \mathrm{kg}$ of maize). Vegetables suffered no major damage since it is cultivated on a small scale and in close proximity

Table 2: Types of crop cultivated and their production. Maize is the main crop cultivated in the study area. 


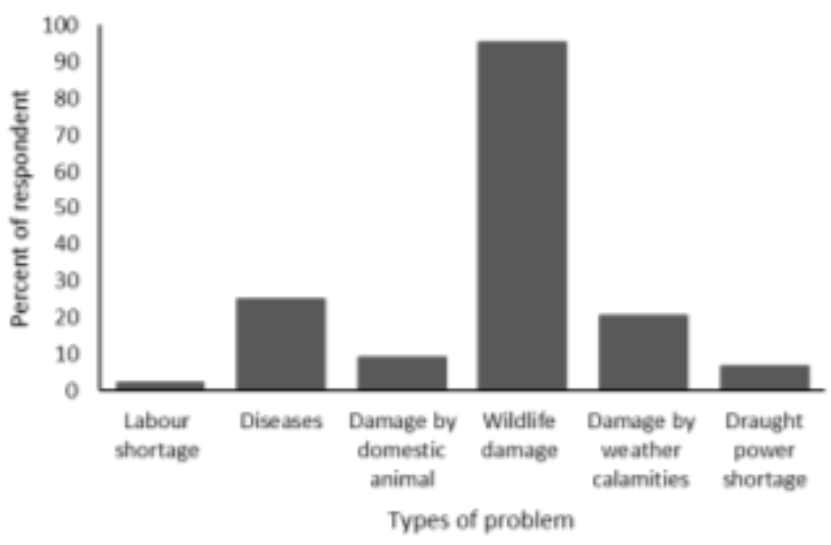

Figure 2: Crop damage by wildlife is reported by $95.5 \%$ of the household and its categorized as one of the major factor affecting crop production in the study area followed by diseases

to the settlements. Some of the respondents expressed their loss in terms of an area which was recorded to be as high as $25 \%$ of their cultivated area. The distribution of the crop loss was highly skewed suggesting crop damage by wild animals does not occur evenly across households. Data revealed that households located near the edge of the

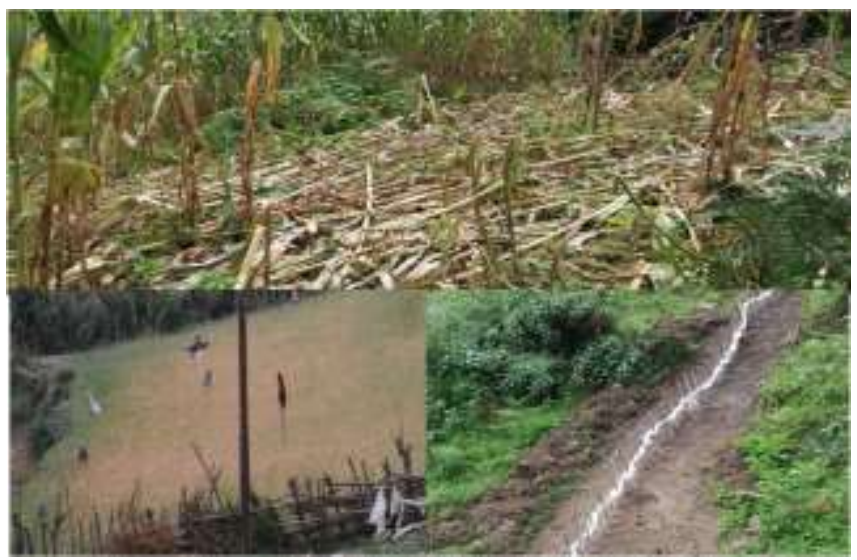

Figure 3: Example of incidences of crop damage and countermeasure adopted by the people in study area : (a) Crop damage by porcupine (b) crop guarding using fencing and scare crows \& (c) barricade for porcupine.

forest sustained significant crop loss in comparison to those located distant from the forest. Incidences of crop damage by the wild animals showed significant correlation with the proximity of the cultivated land to the edge of the forest $(p<0.001)$ in the study area.

Wild animals comprising of deer, bear, pig, monkey, bird, porcupine and squirrels were considered as conflict species in the study area. Porcupine was recorded as the most destructive with the highest mean rank value of 4.69 followed by the monkey (4.32) and wild pig (3.70) in the moderate category. Birds, squirrel, deer, and bear (mean value $\leq 2$ ) were found to be the least destructive. In terms of frequency of crop raiding incidences wild pig $(n=40)$ was reported to be more frequent than a monkey $(n=31)$ after porcupine $(n=42)$.

The nature and magnitude of crop damage by the respective wild animals were reported to be different. Porcupine and wild pig were known to raid the crop at night while monkey and others are active at day time resulting in a need to guard the crop throughout the day and night. Nocturnal conflict species caused damage by uprooting and cutting the stems of standing crops right from the young shoot until harvesting, while diurnal (monkey) destroys the crops at times of maturity.

Crop guarding, use of conventional fencing (fencing made from locally available materials) and scarecrows were some of the widely adopted strategies to minimize the loss of crops to wild animals. Interviewees reported guarding their crop throughout the day and night by actively chasing the wild animals away from crop using dog and building watch-out huts at a strategic location in the field (95.5\%, $\mathrm{n}=42$ ). Making noise by shouting and beating of empty tin left hanging in various parts of the field and keeping the fire burning in the watchout hut were some of the strategies used to scare the animals in the night. Digging of more than one feet high trench along the periphery of the field was also reported to be effective and is used by $4.5 \%$ of the households $(n=2)$. Retaliatory killing of conflict species $(n=1)$ was also reported despite their unwillingness to report the kill with the fear of getting penalized by the forestry laws. $95.5 \%$ reported the use of a combination of two or more measures to ensure effective protection of crops.

In the study area, people spend extensive time in guarding the crops both during day and night. On average a person from each household would guard crops for 75 days and two people for 66 nights. Guarding periods varied from 30 to 150 days and 20 to 150 nights primarily to protect the crop from raiding by wild animals in a year. More people are involved in the night guarding since it is difficult to 
detect the animals in the dark and people are afraid to stay alone in the watch-out hut. The burden of guarding crops during the day falls on school children during weekends where as productive adults is engaged on weekdays and nights irrespective of their gender.

Taking in to account the overall mean guarding days in a season, a household is subjected to an annual loss equivalent to 268.8 US\$ as opportunity cost calculated based on minimum national wage rate at 3.6 US\$ per day. During the study, several areas of fallow land were observed by the authors which were reported to be left uncultivated due to severe crop raiding incidences by wild animals in the past. The fragmented land located at the edge of the forest ranging from 0.5 acre to 1 acre in size was reported to be left uncultivated by $18.2 \%(n=8)$ of households due to the severity of crop damage. Such fallow lands are more common in the village of Murphee. Households also reported extra fuelwood consumption during the night while guarding of the crops.

National parks and protected area management was initially originated with the establishment of Yellowstone National Park to protect natural heritage and cultural identity of the common, which prohibits the use of the resources within it. In the 1960's and 70's Bhutan adopted the American originated conservation ideology with some necessary changes to suit the locality. However, native inhabitants were permitted to reside within the protected area with minimum restriction over their customary right to use the natural resources. Wildlife depredation in the form of crop and livestock damage as a result of habitat protection under the modified conservation ideology remains as a challenge.

Similar to the findings of Mwakatobe, et al. [17] economic loss incurred by the household residing near the protected area from crop damage by wild animals was significant. According to Sukumar [18] most wildlife has a greater affinity for maize due to its high protein content. Such losses may seem insignificant in the global and national level, but they give rise to an exponentially high cost for the households being affected who are dependent on sunsistence agriculture with not much alternative income [2]. Consistent with a number of other studies conducted related to HWC, the data revealed the majority of households located near the edge of forest suffer maximum crop damage as compared to those located distant from the forest [19],[20]. In such pattern, households residing away from the forest edge fail to cooperate with the community to address HWC in much holistic manner.

Households actively use many non-lethal methods to protect their crops from raiding by wild animals. Guarding the crops, use of conventional fencing and scarecrows, making noise by beating old metallic objects, keeping a fire burning in the watch-out hut and digging trenches were some of the methods to keep away the wild animals. Retaliatory killing of conflict species $(n=1)$ was also reported which calls for a need to aware the villagers on existing Forest and Nature Conservation Acts and Rules.

Physical guarding was one of the most widely used methods against crop raiding $(95.5 \%, \mathrm{n}=42)$ mainly due to low capital investment [19].

Porcupines and wild pig are known to raid the crops at night and monkeys during daytime which results in a need to guard the crops throughout day and night. Guarding the crops day and night not only increases the workload but also puts the people at physical risk [21]. The practice of crop guarding by the school children to meet the demand for labor during weekends can have a negative impact on children's education [22]. Meeting future local food security will be challenged with increasing trends of fallow land and people opting for off-farm opportunities as a livelihood option to confront HWC [23]. Extra fuelwood consumption during the night guarding of crops would also mean a considerable amount of time and money being spend for the extraction of fuelwood which will ultimately lead to resource exhaustion.

\section{Conclusion}

The study revealed there is a considerable HWC in communities located at the buffer zone of the sanctuary with $95.5 \%$ of the surveyed households 
confirming the incidence of crop damage by wild animals. Crop raiding by wild animals seems to be very significant in the context of economic value for the people residing in the buffer zone. While the study does not offer a conclusive answer to the question of how to mitigate HWC, it does identify the loss of various crops which can ultimately affect the local food security as one of the major consequences. As porcupine was the most problematic animals which accounts for more than half of the damage done to the crops we recommend further studies on Human-Porcupine conflict in the area.

With agriculture farming being the vital part of community's livelihood, HWC is inevitable in future which calls for wildlife managers, researchers and policymakers to join hands to devise an effective conservation management strategy that fulfills the needs of both wildlife and communities. Installation

\section{Reference}

[1] 1. IUCN, World Park Congress Recommendation V.20. Preventing and Mitigating Human-Wildlife Conflicts . Durban: IUCN, 2003.

[2] 2. Lamarque, F., et al., Human-wildlife conflict in Africa: causes, consequences and management strategies. FAO Forestry Paper, 2009(No.157): p. vii + 98 pp.

[3] 3. Choudhury, A., Human-Elephant Conflicts in Northeast India. Vol. 9. 2004. 261-270.

[4] 4. Distefano, E., Human-Wildlife Conflict worldwide: collection of case studies, analysis of management strategies and good practices. 2005.

[5] 5. Madden, F.M., The Growing Conflict Between Humans and Wildlife: Law and Policy as Contributing and Mitigating Factors. Journal of International Wildlife Law \& Policy, 2008. 11(2-3): p. 189-206.

[6] 6. Woodroffe, R., Thirgood, S., \& Rabinowitz, A., People and Wildlife, Conflict or Co-existence? Conservation Biology. 2005, Cambridge: Cambridge University Press.

[7] 7. Messmer, T.A., The emergence of human-wildlife conflict management: of solar and electric fencing can be one way to ease crop depredation due to its effectiveness against wider range of the animals. However, installation of electric/solar fencing is a short term mitigation measures.

While it is of utmost priority to conserve our nature and wildlife, the welfare of our people cannot be overlooked. Thus the sustainable HWC management regimes should be explored.

\section{Acknowledgement}

Authors are thankful to the management of Sakteng Wildlife Sanctuary and their field staffs for every possible help while conducting this study. Authors are also sincerely thankful to Dr. Joanne Millar, Senior research fellow, Charles Sturt University and Mr. Sangay Wangchuk, Research Officer, Ugyen Wangchuk Institute for Conservation and Environmental Research for their valuable inputs in finalizing the paper

turning challenges into opportunities. International Biodeterioration \& Biodegradation, 2000. 45(3): p. 97-102.

[8] 8. Sekhar, N.U., Crop and livestock depredation caused by wild animals in protected areas: the case of Sariska Tiger Reserve, Rajasthan, India. Environmental Conservation, 2002. 25(2): p. 160-171.

[9] 9. Barirega, A., et al., The Effects of Crop Raiding on Household Food Security in the Albertine Rift: A Case Study of Queen Elizabeth National Park, Western Uganda. Human Dimensions of Wildlife, 2010. 15(1): p. $45-54$.

[10] 10. Barua, M., S.A. Bhagwat, and S. Jadhav, The hidden dimensions of humanwildlife conflict: Health impacts, opportunity and transaction costs. Biological Conservation, 2013. 157: p. 309-316.

[11] 11. Kaswamila, A., S. Russell, and M. McGibbon, Impacts of Wildlife on Household Food Security and Income in Northeastern Tanzania. Human Dimensions of Wildlife, 2007. 12(6): p. 391-404.

[12] 12. NSB, National Statistics Bureau. (2014). Bhutan Poverty Assessment. National Statistics Bureau. 2014. 
[13] 13. MoAF, Technical report Bhutan land cover assessment 2010. Ministry of Agriculture and Forest. Ministry of Agriculture and Forest,2011.

[14] 14. Ogra, M.V., Human-wildlife conflict and gender in protected area borderlands: A case study of costs, perceptions, and vulnerabilities from Uttarakhand (Uttaranchal), India. Geoforum, 2008. 39(3): p. 1408-1422.

[15] 15. MoAF, Bhutan States of Parks. Department of Forest and Park Services, Ministry of Forest and Agriculture, Royal Government of Bhutan, 2016.

[16] 16. FRMD, National Forest Inventory Report Vol I. Department of Forest and Park Services, Bhutan. 2016.

[17] 17. Mwakatobe, A., et al., The impact of crop raiding by wild animals in communities surrounding the Serengeti National Park, Tanzania. Vol. 6. 2014. 637-646.

[18] 18. Sukumar, R., Ecology of the Asian elephant in southern India. I. Movement and habitat utilization patterns. Vol. 5. 1989. 118.

[19] 19. Wang, S., P. Curtis, and J. Lassoie, Farmer Perceptions of Crop Damage by Wildlife in Jigme Singye Wangchuck National Park, Bhutan. Vol. 34. 2006. 359365.

[20] 20. Gobosho Amaja, L., D. Feyssa, and T. Gutema, Journal of Ecology and the Natural Environment Assessment of types of damage and causes of human-wildlife conflict in Gera district, south western Ethiopia. Vol. 8. 2016. 49-54.

[21] 21. Ogra, M. and R. Badola, Compensating Human-Wildlife Conflict in Protected Area Communities: Ground-Level Perspectives from Uttarakhand, India. Vol. 36. 2008. 717-729.

[22] 22. Walpole, M., et al., Wildlife and People: Conflict and Conservation in Masai Mara, Kenya. 2003.

[23] 23. Hua, X., et al., Wildlife damage and cultivated land abandonment: Findings from the mountainous areas of Chongqing, China. Crop Protection, 2016. 84: p. 141-149. 